\title{
Associations between loneliness and perceived social support and outcomes of mental health problems: a systematic review
}

\author{
Jingyi Wang ${ }^{1}$, Farhana Mann ${ }^{1}$, Brynmor Lloyd-Evans ${ }^{1}$, Ruimin Ma ${ }^{1}$ and Sonia Johnson ${ }^{1,2^{*}}$
}

\begin{abstract}
Background: The adverse effects of loneliness and of poor perceived social support on physical health and mortality are established, but no systematic synthesis is available of their relationship with the outcomes of mental health problems over time. In this systematic review, we aim to examine the evidence on whether loneliness and closely related concepts predict poor outcomes among adults with mental health problems.

Methods: We searched six databases and reference lists for longitudinal quantitative studies that examined the relationship between baseline measures of loneliness and poor perceived social support and outcomes at follow up. Thirty-four eligible papers were retrieved. Due to heterogeneity among included studies in clinical populations, predictor measures and outcomes, a narrative synthesis was conducted.

Results: We found substantial evidence from prospective studies that people with depression who perceive their social support as poorer have worse outcomes in terms of symptoms, recovery and social functioning. Loneliness has been investigated much less than perceived social support, but there is some evidence that greater loneliness predicts poorer depression outcome. There is also some preliminary evidence of associations between perceived social support and outcomes in schizophrenia, bipolar disorder and anxiety disorders.

Conclusions: Loneliness and quality of social support in depression are potential targets for development and testing of interventions, while for other conditions further evidence is needed regarding relationships with outcomes.
\end{abstract}

Keywords: Loneliness, Perceived social support, Outcomes, Mental health problems, Systematic review

\section{Background}

There is increasing interest in the effects of social relations on health, and in the service delivery and policy implications of such effects [1]. Loneliness has been a particularly prominent focus in recent research on physical health [2-4]. For instance, two meta-analytic reviews have reported that loneliness and poor social support are associated with higher mortality rates, and that the effect is comparable with some well-established risk factors such as obesity, physical inactivity, and smoking

\footnotetext{
* Correspondence: s.johnson@ucl.ac.uk

${ }^{1}$ Division of Psychiatry - University College London, 6th Floor, Maple House, 149 Tottenham Court Road, London W1T 7NF, England

${ }^{2}$ Camden and Islington NHS Foundation Trust, St Pancras Hospital, 4 St Pancras Way, London NW1 OPE, England
}

$[5,6]$. They are also predictive of development of coronary heart disease and stroke [7], increases in systolic blood pressure $[8,9]$, and chronic pain $[10,11]$ in longitudinal studies. The effect of loneliness on physical health may be via biological, psychological and/or behavioural mechanisms, including physiological functioning, neuroendocrine effects, gene effects, immune functioning, perception of stressful events, health behaviours and sleep quality $[2,12,13]$. In contrast, while loneliness and lack of social support are well-documented problems among mental health service users [14], they have not been prominent in research, mental health service delivery and policy. Until recently, there has tended to be less focus on the social determinants of mental health than on genetics and neurobiology, but recent integrated aetiological models,

(c) The Author(s). 2018 Open Access This article is distributed under the terms of the Creative Commons Attribution 4.0 International License (http://creativecommons.org/licenses/by/4.0/), which permits unrestricted use, distribution, and reproduction in any medium, provided you give appropriate credit to the original author(s) and the source, provide a link to the Creative Commons license, and indicate if changes were made. The Creative Commons Public Domain Dedication waiver (http://creativecommons.org/publicdomain/zero/1.0/) applies to the data made available in this article, unless otherwise stated. 
such as the integrated sociodevelopmental-cognitive model, bring social factors into the neuroscientific mainstream, with increasing evidence that such factors need to be included to achieve models of good explanatory value [1517]. An increasing focus on loneliness has also been driven by recognition of its high prevalence, and of its wide ranging impacts on physical health and mental well-being [17]. Despite this increasing recognition of its importance, to date no systematic synthesis of the evidence on the relationship between loneliness and the outcomes of mental health problems has been published.

Loneliness has been defined as a negative emotional state that occurs when there is "a discrepancy between... the desired and achieved patterns of social interaction" [18]. Loneliness is sometimes seen as an essentially unidimensional concept, sometimes as comprising two dimensions. Weiss [19] proposed a multidimensional concept of loneliness, categorising loneliness into social and emotional dimensions. Social loneliness derived from "the absence of socially integrative relationships", while emotional loneliness stemmed from the absence of "a close emotional attachment" [19]. Social loneliness occurs when a person does not have a wider social network as desired, which can lead to the feelings of boredom, exclusion and marginality $[19,20]$. In contrast, emotional loneliness occurs when someone is missing an intimate relationship, which can result in distress and apprehension $[19,20]$. Psychometrically robust self-report measures of loneliness have been developed and used extensively in research on physical health and on older people, including the University of California at Los Angeles (UCLA) Loneliness Scale [21] and the de Jong-Gierveld Loneliness Scale [22]. Feelings of loneliness are more prevalent among people with mental illness than in the general population [23, 24]. In a study of older adults with major depression, dysthymia, or minor depression, $83 \%$ of the respondents reported loneliness and $38 \%$ reported severe loneliness [25]. By comparison, only 32\% of non-depressed elderly people were lonely and $4 \%$ severely lonely using the same loneliness scale [26]. In a comparison of people with psychosis and a general population sample with similar demographic characteristics, the prevalence of loneliness among people with psychosis was $79.9 \%$ compared with $35 \%$ in the general population [27]. For people with depression, cross-sectional studies have found up to $40 \%$ of respondents feeling lonely most of the time [28], with a tenfold increase in the odds of being lonely compared to the general population [29].

Given the high prevalence of loneliness among people with mental health problems and the evidence for its harmful effects in other populations, good quality evidence is needed on its impact on recovery from mental health problems and on the health and social functioning of mental health service users. This has potential to inform the development of preventive and therapeutic interventions for which there is not as yet an evidence base. An important question in evaluating the available evidence is how far loneliness is conceptually and empirically distinct from other concepts and measures related to social relationships. Loneliness has been shown to be only moderately correlated with more objectively measured concepts such as social isolation, social network size and objective social support received from others [30, 31]. However, subjectively rated concepts related to social relationships are less easy to distinguish clearly from loneliness [32]. For example, perceived social support refers to people's beliefs about how much support is potentially available from their relationships and social contacts and about the quality of this support [33, 34]. This is distinct from received social support, a rating of how often someone reports receiving particular supportive behaviours [33, 34]. Measures of perceived social support assess the quality or adequacy of social support from a subjective perspective. For instance, the two widely used measures, the Multi-dimensional Scale of Perceived Social Support (MSPSS) [35] and the Subjective Support Subscale of Duke Social Support Index (DSSI) [36], consist of items such as "How often do you feel lonely?", "Can you talk about your deepest problems?", "I have friends with whom I can share joys and sorrows", which have a high degree of overlap with loneliness measures. Likewise, measures of confiding relationships assess the extent to which people feel close to and able to talk intimately with other people [37, 38]. Studies have found large negative correlations between loneliness and perceived social support [39-42]. Thus these concepts resemble loneliness as subjective evaluations of the quality and impact of social relationships: given this conceptual overlap, this paper includes them along with loneliness.

Three previous systematic reviews have explored the relationship between social relations and depression in general population [43,44], or older adults [45], but included both cross-sectional and prospective studies. One further review looked at the relationship between social networks and support and early psychosis in people with first episode psychosis and in general population samples, but included no prospective studies [46]. To our knowledge, there is no systematic review which summarises and synthesises the evidence regarding the relationship between loneliness and perceived social support and the course of existing mental health problems, and which includes only prospective studies, from which inferences about the direction of causation may be drawn. Our review will fill this gap, and will provide useful evidence about how far and in what context loneliness and perceived social support may influence mental health recovery. Thus the aim of the current paper is to 
synthesise the available evidence as to whether higher levels of loneliness and poorer perceived social support have an adverse effect on outcomes in adults of all ages with existing mental health problems.

\section{Methods}

A systematic review was conducted of the scientific literature addressing the question of whether loneliness and low perceived social support are associated longitudinally with poorer outcomes among adults of all ages with a range of mental health problems. The review's protocol was registered on PROSPERO, which is an international database of prospective systematic reviews with health related outcomes (registration number: CRD42015014784) [47].

\section{Inclusion criteria}

Types of study: The review included longitudinal studies in which the relationship between baseline measures of loneliness and poor perceived social support and outcomes at follow up was examined using quantitative measures.

Participants: Participants in the included studies were adults with mental illnesses, specifically schizophrenia and schizoaffective disorder, psychosis in general, depression, bipolar disorder, and anxiety disorders. Clinical populations were included however diagnosis was made, for example clinical diagnoses, ratings according to the criteria of the Diagnostic and Statistical Manual of Mental Disorders (DSM) or the International Classification of Diseases (ICD), or use of reliable and valid instruments such as the Mini-International Neuropsychiatric Interview (M.I.N.I.). We excluded studies with samples of children under 16 years old, people with intellectual disabilities or organic mental disorders including dementia, or cohorts assembled on the basis of a primary physical illness diagnosis.

Exposure variables: Included studies used quantitative measures of loneliness or of related concepts that involve a subjective rather than objective appraisal of social relationships, such as perceived social support or confiding relationships. Concepts based on objective ratings of the size and functioning of social networks, such as social isolation and social network size, were excluded. Social capital was also excluded as it relates to characteristics of society or communities as a whole as well as individuals' appraisal of their relationships, and is conceptually distinct from loneliness [32]. We included studies only if exposure variables assessed subjective appraisal of overall social connectedness, rather than the quality of specific relationships: therefore, measures of support from partner and quality of a specific significant relationship were excluded.

Outcomes: The review included a wide variety of outcomes, ranging from clinical outcomes to functioning outcomes. Studies in which any of the following outcomes were measured at follow-up were eligible for inclusion:

1) Relapse: recurrent episodes following recovery at baseline of mental illness meeting the criteria of DSM or ICD, or of other reliable and valid instruments such as the Center for Epidemiologic Studies Depression Scale (CES-D), and proxy measures of acute relapse such as admission to psychiatric hospital/crisis services/acute mental health services.

2) Measures of functioning or of recovery: recovery of function, social functioning, self-rated recovery, quality of life, and disability.

3) Symptom severity: level of symptoms, symptom improvement or deterioration.

4) Global outcome: overall outcome rating combining different aspects of mental health and functioning, such as the Health of the Nation Outcome Scales (HoNOS).

\section{Search strategy}

A systematic search of the following six electronic databases was undertaken: Medline, PsycINFO, Embase, Web of Science, CINAHL and Cochrane Library (1891 to April 2016). No language and publication period restrictions were applied. Search terms for loneliness and related concepts were combined with terms for mental disorders and outcomes. Searches were conducted using both subject headings (MeSH terms) and text words within title and abstract. Search terms were adapted as required for different databases (for full details, see Additional file 1). The search terms used in Medline are as follows:

1) Loneliness: loneliness [MeSH] OR loneliness OR lonely OR social support adj5 (subjective or personal or perceived or quality) OR confiding relationship*

2) Mental disorders: mental disorders [MeSH]. exp. OR mental OR psychiatr* OR schizo* OR psychosis OR psychotic OR depress* OR mania* OR manic OR bipolar adj5 (disorder or disease or illness) OR anxiety disorders $[\mathrm{MeSH}]$. exp.

3) Outcomes: prognosis $[\mathrm{MeSH}] \mathrm{OR}$ outcome* OR recurren* OR relapse OR admission OR hospitali?ation OR crisis OR admitted OR detained OR detention OR recovery of function [MeSH] OR "social functioning" OR "self-rated recovery" OR "quality of life" OR "symptom severity" OR disability

Apart from outcome terms, we searched "onset" and related terms as searches were conducted simultaneously 
for this and a companion systematic review on loneliness as a risk factor for the onset of psychiatric disorders in the general population. Reference lists of studies identified through the electronic search for inclusion in the review and of review articles were manually searched for further relevant studies. Relevant studies reported in dissertations, conference reports or other sources other than published journals were searched using the free text and keyword searches from the following two sources: Zetoc (indexing and abstracting database of conference proceedings) and OpenGrey (system for information on grey literature in Europe). When necessary and possible, we sent emails to authors to request full text or clarify some uncertainties.

Selection of studies for inclusion in the review was made independently by two reviewers (J.W. \& F.M.). Titles of all identified studies were screened. The abstracts of potentially relevant studies were read; the full text of studies still considered potentially relevant was then retrieved and read. All studies included by one assessor were confirmed by the other reviewer to check adherence to inclusion criteria in study selection. 800 studies excluded by one assessor were checked by the other reviewer to establish reliability of our study selection. The agreement between reviewers was higher than $99 \%$. Queries about inclusion/exclusion were resolved through discussion with a third reviewer (S.J.).

\section{Data extraction, quality assessment and synthesis}

A structured template was developed to extract relevant data from eligible papers. Two review authors (J.W. \& F.M.) independently extracted data and assessed their methodological quality. Extracted data and quality assessment scores were checked by a second reviewer for $20 \%$ of papers. Disagreements between the two assessors were resolved through discussion with a third review author (S.J.). The methodological quality of each study included in the review was assessed using a standard form adapted from the Mixed Methods Appraisal Tool (MMAT) - Version 2011 [48]. The MMAT has been designed for appraisal of the methodological quality for qualitative, quantitative and mixed methods studies. For quantitative studies it includes criteria relevant to randomised controlled, non-randomised, and descriptive studies. For the purposes of our review, we used the criteria for the quantitative non-randomised domain (Cohort study version). As there are four criteria for this domain following two screening questions, the overall quality score was presented using descriptors $*$, **, ***;, and $* * * *$, ranging from * (one criterion met) to **** (all criteria met). The four criteria related to selection bias, measurement quality, adjustment for confounders, and percentage of complete outcome data/response rate/ follow-up rate (see Additional file 2). We conducted a narrative synthesis of results as the anticipated heterogeneity of included studies, for example in samples, predictor measures and outcomes, made a meta-analysis inappropriate. The main results have been stratified by type of mental health problem investigated and tables and text were used to summarise the data.

\section{Results}

\section{Literature search}

Our initial database search retrieved 13,076 records (see Fig. 1). After excluding duplicates and screening titles and abstracts to exclude obviously irrelevant papers, 797 full-text articles were assessed for eligibility. 734 studies were excluded because: i) they were not longitudinal quantitative studies; ii) they assessed a form of social relationships conceptually distinct from loneliness or perceived social support; iii) they analysed the relationship between change scores in loneliness and outcome variables, rather than baseline loneliness as a predictor of outcome; or iv) they investigated a sample consisting of children under 16 years old or of people with primary diagnoses of drug and alcohol disorders, personality disorders, post-traumatic stress disorder (PTSD), learning disabilities or organic mental disorders, or of people recruited as having specific physical illnesses. Twenty-two further papers were retrieved by hand-searching the reference lists of the papers already identified. Of the resulting 85 studies, 34 articles about outcomes of mental disorders among people with existing mental health problems were included in this review. The other $51 \mathrm{pa}$ pers will be reported in a companion systematic review regarding the relationship between loneliness and onset of mental health problems in the general population. The search results are reported as a Prisma diagram in the Fig. 1.

\section{Eligible papers}

The 34 eligible papers were from seven countries, including 23 from North America, 10 from Europe and one from Israel. These papers consisted of 23 studies with samples of people with depression, two focusing on schizophrenia or schizoaffective disorders, four on bipolar disorder, and three on anxiety disorders. Two further studies included people with a mixture of mental health problems (Table 1). Only two studies directly assessed loneliness, and most of the studies used various scales to measure perceived social support. Nearly half of included papers studied symptom severity as an outcome, a third of the papers assessed recovery/remission, and a third of the papers included other outcomes such as quality of life, disability pension qualification, functional impairment or life satisfaction. The sample sizes of six studies in our review exceeded 400, 22 were between 100 and 400, and six were less than 100. Six studies had 


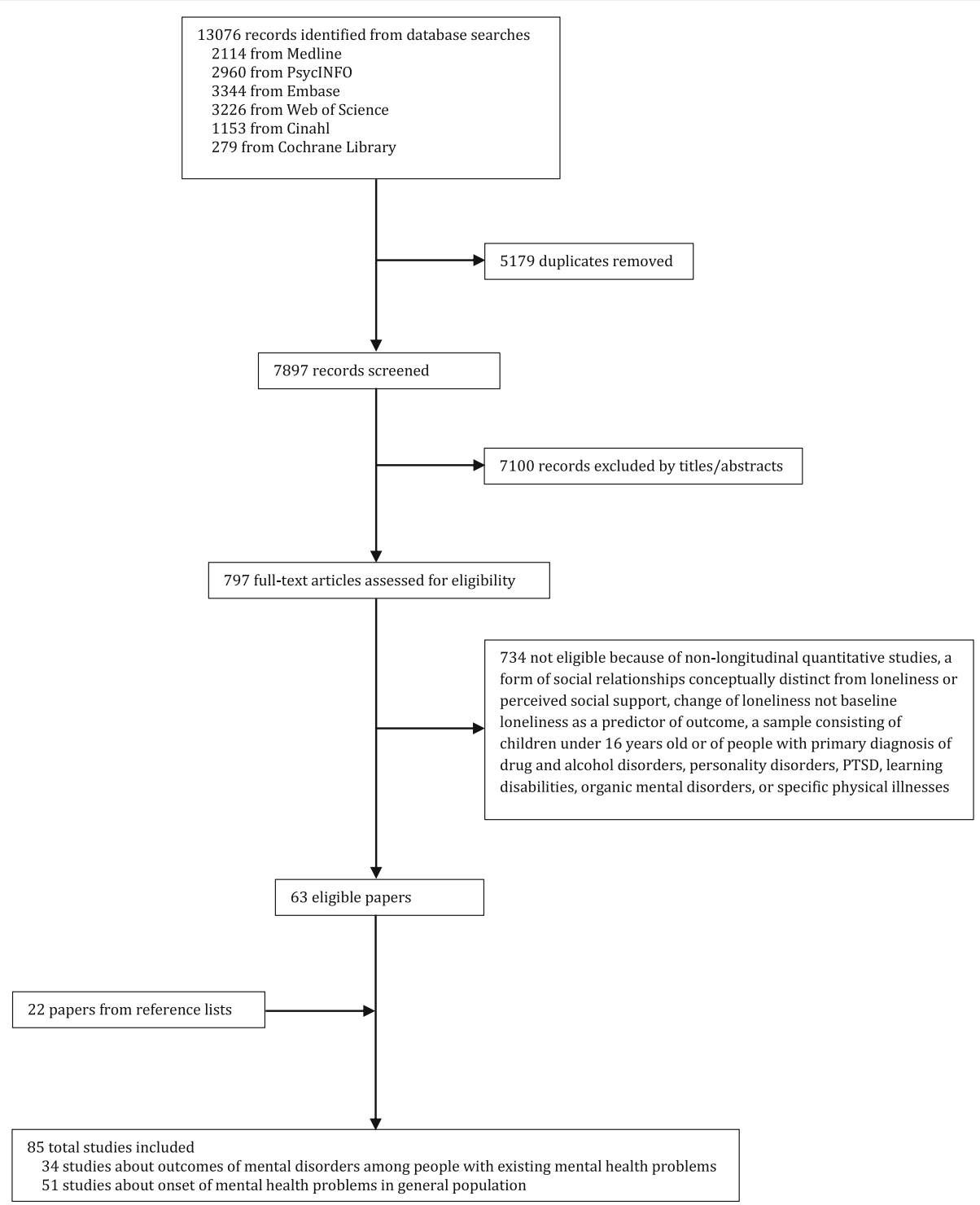

Fig. 1 Studies selection flowchart

short length of follow-up (less than one year), 23 following up the cohorts for one to two years, and five for over two years. With regard to quality assessment, five studies were assigned a maximum score of four (****) as their overall quality scores, 16 studies had a score of three $(* * *)$ and 13 papers had two $(* *)$ according to the appraisal criteria of MMAT. Most studies had lower quality assessment ratings because they did not report the percentage of complete outcome data, response rate or follow-up rate (for full details, see Additional file 2).

\section{Depression}

Among the 23 papers with samples of people with depression, 13 studies assessed depression severity as an outcome. Eleven of these found that poorer perceived social support or greater loneliness at baseline was a significant predictor of higher depressive symptom severity at follow-ups (Table 2). Nine of these eleven papers conducted multivariable analyses including adjusting for baseline depression severity. In eight of these nine papers, the relationship between baseline loneliness and depressive symptom outcome remained significant. For example, among the three studies with high quality scores $(* * * *)$, Blazer and colleagues [49] and Brugha and colleagues [50] followed cohorts of adults with depression in America and the UK respectively. They reported that poorer subjective social support at baseline was predictive of poorer outcomes at follow-up, outcomes including poorer life satisfaction (beta $=0.10$, $\mathrm{B}=0.37$ ), worse depressive symptoms (beta $=0.10, \mathrm{~B}=$ 0.30 ) [49], and more severe psychiatric status (regression coefficient $=-1.46$ ) [50]. In the third study rated as high 


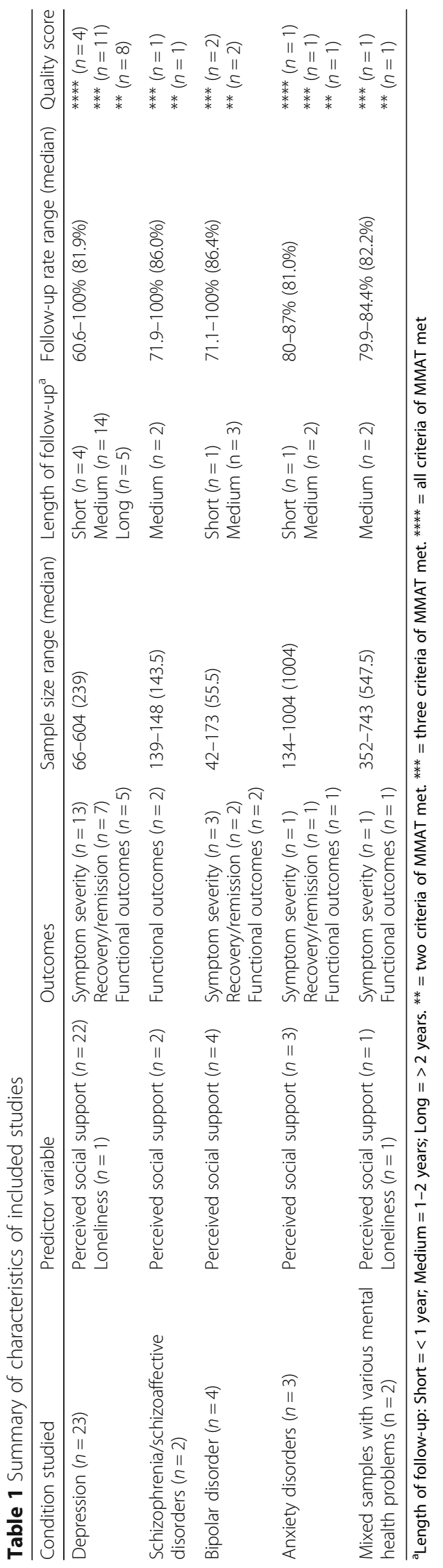


Table 2 Summary of findings on depression

\begin{tabular}{|c|c|c|c|}
\hline Reference & $\begin{array}{l}\text { Predictor } \\
\text { variable }\end{array}$ & Outcome variable & $\begin{array}{l}\text { Results ( }++<0.05 \text { adjusted; }+<0.05 \text { unadjusted; - } \\
\text { non-significant) }\end{array}$ \\
\hline Hybels et al. (2016) [79] & $\begin{array}{l}\text { Perceived social } \\
\text { support }\end{array}$ & $\begin{array}{l}\text { Trajectory class } \\
\text { (quick recovery, } \\
\text { slow recovery, } \\
\text { persistent moderate, } \\
\text { and persistent high) }\end{array}$ & $\begin{array}{l}++ \text { Patients in the persistent moderate depression class had } \\
\text { lower levels of baseline subjective social support compared } \\
\text { with patients in the quick recovery class (OR }(95 \% \mathrm{Cl})=0.91 \\
(0.83,0.98)) \text {. Patients in the persistent high depression class } \\
\text { had lower levels of baseline subjective social support } \\
\text { compared with those in the quick recovery class }(\mathrm{OR}(95 \% \mathrm{Cl}) \\
=0.83(0.75,0.92))\end{array}$ \\
\hline Holvast et al. (2015) [25] & Loneliness & $\begin{array}{l}\text { Symptom severity; } \\
\text { Remission }\end{array}$ & $\begin{array}{l}++ \text { In the fully adjusted model, a 1-point higher baseline } \\
++ \text { loneliness score predicted a } 0.61 \text {-point higher depressive } \\
\text { symptom severity score at follow-up (Beta }=0.61,95 \% \\
\text { Cl } 0.12-1.11, p=0.02 \text { ). Logistic regression analysis showed } \\
\text { that while adjusting for social network size and potential } \\
\text { confounders, the very severely lonely respondents were } \\
\text { less likely to achieve remission from their depressive disorder } \\
\text { compared with the non-lonely respondents (OR }=0.25,95 \% \\
\text { Cl } 0.08-0.80, p=0.02 \text { ). }\end{array}$ \\
\hline
\end{tabular}

Holma et al. (2012) [54]_ Perceived social Disability pensions support

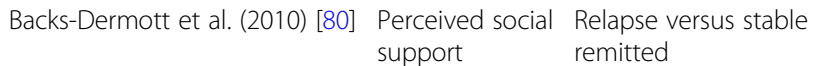

Bosworth et al. (2008) [81]

Rytsala et al. (2007) [55]

Rytsala et al. (2006) [56]

Leskela et al. (2006) [51]

Steffens et al. (2005) [82]

Ezquiaga et al. (2004) [83]
Perceived social Depression severity support

Perceived social Work disability support allowances

Perceived social Functional disability; support Social and work adjustment: Days spent ill in bed or not

Perceived social Severity of depression support

Perceived social Severity of depression support

Perceived social Episode remission support $+\quad$ Lower perceived social support at baseline predicted greater likelihood of being granted a disability pension over 5 year follow-up on univariate analysis ( $p=0.031$ ), but not significant in multivariate analyses where the outcome was the interval time to the date the pension was granted

++ Lower perceived social support from a significant other (standardized discriminant function coefficient 0.48) and lower perceived social support from friends (standardized coefficient 0.35) at baseline predicted greater likelihood of depressive relapse at one-year follow-up. The Discriminant Function Analysis was significant, Wilk's Lambda $=0.69, x^{2}$ (5) $=16.35, p=0.006$

++ Poorer subjective social support was a significant predictor of more severe depression at 12 months. Standardized beta $=-0.13, p=0.05$

+ Lower perceived social support at 6 month was a significant predictor of greater likelihood of being granted disability allowances at 18 months ( $F=6.3, p=0.013)$, but not significant in multivariate analysis

++ Lower perceived social support at baseline was a significant ++ predictor of more severe functional disability at 6 months

- $\quad(B=0.232, \beta=0.210, p=0.002,95 \% \mathrm{Cl} 0.084$ to 0.379$)$, and poorer social and work adjustment at 6 months $(B=-0.008$, $\beta=-0.222, p=0.001,95 \% \mathrm{Cl}-0.013$ to -0.003$)$. Lower perceived social support at 6 months was one of the most significant factors predicting more severe functional disability at 18 months $(B=0.240, \beta=0.215, p=0.002,95 \% C l 0.088$ to $0.393)$, and poorer social and work adjustment at 18 months $(B=-0.011, \beta=-0.303, p<0.001,95 \% C l-0.015$ to -0.006$)$. But perceived social support did not predict any days spent ill in bed or not

+ Lower perceived social support at 6 months predicted more severe depression at 18 months in original zero-order correlation $(r=-0.392, p<0.001)$ and within-group standardised correlation $(r=-0.230, p=0.001)$ among all patients, but not significant in multivariate analysis. In full remission group at 6 months $(n=67)$, lower perceived social support at 6 months predicted higher level of depressive symptoms at 18 months in multivariate analysis $(r=-0.321, p=0.012)$

++ Lower subjective social support at baseline predicted more severe depression over time (estimate $-0.5641, p=0.0002$ )

- Higher perceived social support at baseline did not predict remission at 12 months in univariate analysis ( $p=0.33)$, and it was not included in multivariate analysis 
Table 2 Summary of findings on depression (Continued)

\begin{tabular}{lll}
\hline Reference & $\begin{array}{l}\text { Predictor } \\
\text { variable }\end{array}$ & Outcome variable \\
\hline Reference & $\begin{array}{l}\text { Predictor } \\
\text { variable }\end{array}$ & Outcome variable \\
Gasto et al. (2003) [84] & $\begin{array}{l}\text { Perceived social } \\
\text { support }\end{array}$ & $\begin{array}{l}\text { Severity of residual } \\
\text { symptoms }\end{array}$ \\
Bosworth et al. (2002) [53] & $\begin{array}{l}\text { Perceived social } \\
\text { support }\end{array}$ & Time-to-remission \\
Bosworth et al. (2002) [52] & $\begin{array}{l}\text { Perceived social } \\
\text { support }\end{array}$ & $\begin{array}{l}\text { Remission } \\
\text { Triesch (2002) [85] }\end{array}$ \\
Perceived social & $\begin{array}{l}\text { Severity of depressive } \\
\text { symptoms; }\end{array}$ \\
support & Quality of life \\
Hays et al. (2001) [57] & Perceived social & $\begin{array}{l}\text { Activities of daily living } \\
\text { support }\end{array}$
\end{tabular}
support Oxman and Hull (2001) [86] $\quad \begin{aligned} & \text { Perceived social Depression severity } \\ & \text { support }\end{aligned}$

Brummett et al. (2000) [87]

Sherbourne et al. (1995) [88]

Blazer et al. (1992) [49]

Blazer et al. (1991) [89]

Brugha et al. (1990) [50]
Perceived social Depressive symptoms support

Perceived social Number of depressive support symptoms
Perceived social Symptom severity
Perceived social Decreased life satisfaction support symptoms; Endogenous symptoms

Perceived social Depressive symptoms support support
Results ( $++<0.05$ adjusted; $+<0.05$ unadjusted; non-significant)

Results ( $++<0.05$ adjusted; $+<0.05$ unadjusted; non-significant)

++ Lower subjective social support at baseline predicted higher intensity of residual symptoms at 9 months in remitters (standardized $\beta=0.41, p<0.001$ )

++ Lower subjective social support at baseline (Hazard Ratio $=0.47,95 \%$ Cl: $0.31-0.71, p=0.003)$ was a significant predictor of longer time to remission

++ Lower baseline levels of subjective social support $(\mathrm{OR}=1.21,95 \% \mathrm{Cl}: 1.09-1.35, p<0.001)$ predicted poorer recovery one year later

- Lower perceived social support at baseline did not

- $\quad$ predict more severe depression $(\beta=-0.17)$ or poorer quality of life $(\beta=-0.12)$ at 3 months

++ There was modest support for hypothesis that baseline subjective social support predicted functional declines at 1 year. There was partial support for hypothesis that the buffering effects of social support against functional decline would be strongest among the most severely depressed patients

++ Greater perceived social support predicted subsequent decreases in depression among participants randomly assigned to placebo group (6-week depression - 0.18, $p<0.05$; 11 -week depression $-0.22, p<0.05$ ), but not significant among paroxetine group or Problem-Solving Treatment for Primary Care group

- Higher levels of received support at baseline significantly predicted decreases in depressive symptoms at both 6 months and 1 year, whereas subjective support did not significantly predict changes in depressive symptoms at either point in time

++ Decreased number of depressive symptoms between baseline and 2-year follow-up was predicted by social support at baseline (standardised regression coefficients $=0.12$, zero-order Pearson product-moment correlations $=0.16, p<0.05)$. Among the subset of patients who had current depressive disorder at baseline, perceived social support was not significantly related to remission. Among patients without current depressive disorder at baseline (subthreshold depression), patients with higher level of perceived social support were less likely to experience a new depressive episode during 2-year period: odds ratio $=0.96(\mathrm{Cl}: 0.95,0.98)$

++ Impaired subjective support at baseline was predictive of poorer outcome at 12-month follow-up in both models: decreased life satisfaction symptoms $(b=0.10, B=0.37$, $p \leq 0.001)$, endogenous symptoms ( $\mathrm{b}=0.10, \mathrm{~B}=0.30, p \leq 0.01)$

$+\quad$ Intercorrelation between social support at baseline and depression score at 6 months: $-0.41, p<0.001$. Intercorrelation between social support at baseline and depression score at 12 months: $-0.34, p<0.001$

++ After controlling for the two significant clinical predictors, a significant main effect was found in total sample for lower satisfaction with support at baseline on more severe psychiatric status at 4 months (regression coefficient $=-1.46, p<0.05$ ) 
Table 2 Summary of findings on depression (Continued)

\begin{tabular}{llll}
\hline Reference & $\begin{array}{l}\text { Predictor } \\
\text { variable }\end{array}$ & Outcome variable & $\begin{array}{l}\text { Results }(++<0.05 \text { adjusted; }+<0.05 \text { unadjusted; }- \\
\text { non-significant) }\end{array}$ \\
\hline George et al. (1989) [90] & $\begin{array}{l}\text { Perceived social } \\
\text { support }\end{array}$ & $\begin{array}{l}\text { Depressive symptoms } \\
\text { Krantz and Moos (1988) [91] }\end{array}$ & $\begin{array}{l}\text { Impaired subjective social support at baseline is a } \\
\text { significant predictor of higher numbers of CES-D } \\
\text { symptoms at follow-up }(b=8.88, B=0.20, p \leq 0.05)\end{array}$ \\
& $\begin{array}{l}\text { Perceived social } \\
\text { support }\end{array}$ & $\begin{array}{l}\text { Remitted, partially } \\
\text { remitted, and } \\
\text { nonremitted }\end{array}$ & $\begin{array}{l}\text { Lower quality of relationships at baseline predicted } \\
\text { poorer remission status after } 1 \text { year }\left(x^{2}=10.21, p<0.01\right)\end{array}$
\end{tabular}

quality, Leskela and colleagues [51] assessed adults with major depressive disorder and found that lower perceived social support six months after initial assessment predicted more severe depression at 18 months among all participants, although this relationship only remained significant in multivariable analysis for the group who had remitted following initial assessment $(r=-0.321)$. The only study using loneliness as a predictor of depression outcomes was conducted by Holvast and colleagues [25] among Dutch older adults. They found that a 1-point higher loneliness score was predictive of a 0.61-point higher depressive symptom severity score at follow-up (Beta $=0.61$, 95\% CI 0.12-1.11). For studies which reported beta as the effect size, beta ranged from 0.10 to 0.61 . Among the 13 studies, three articles had high quality $\left({ }^{* * * * *)}\right)$, four had medium quality $\left({ }^{* * * *}\right)$, and the other six received low quality ratings (**). However, no obvious relationship was found between study quality and whether results were significant.

Six out of seven articles which used recovery/remission of depression as their outcomes reported lower perceived social support or higher loneliness at baseline as a significant predictor of lower rates of recovery/remission at follow-up. Three of the seven studies adjusted for baseline depression severity, and all of them reported significant results. For example, in the study of Holvast et al. [25], the lonely respondents at baseline were reported to be less likely to achieve remission from their depressive disorder at follow-up compared with the non-lonely respondents $(\mathrm{OR}=0.25,95 \% \mathrm{CI} 0.08-0.80)$. Similarly, poorer perceived social support at baseline was a significant predictor of poorer recovery one year later $(\mathrm{OR}=1.21,95 \%$ CI 1.09-1.35) [52], and of longer time-to-remission in a study of initially depressed elderly individuals (Hazard Ratio $=0.47$, 95\% CI 0.31-0.71) [53]. However, none of the seven studies had high quality scores $(* * *)$, with five receiving medium $(* * *)$, and two low scores $(* *)$.

With regard to functional outcomes (five articles), three studies have found that lower perceived social support at baseline was a significant predictor of greater likelihood of being granted disability pensions during the follow-up period (no effect size reported) [54, 55] and of more severe functional disability (beta 0.210 to 0.215, 95\% CI 0.084-0.393) [56]. There is also evidence that greater perceived social support predicted better social and work adjustment (beta -0.222 to -0.303 , 95\% CI -0.013 to -0.006 ) [56], and buffered functional declines in performance on activities of daily living (no effect size reported) [57]. However, after adjustment for potential confounders only two $[56,57]$ of the five studies had significant results.

\section{Schizophrenia/schizoaffective disorders}

Two studies assessed patients with schizophrenia or schizoaffective disorders to identify psychosocial predictors of health-related quality of life and functional outcomes (Table 3). Ritsner and colleagues [58] followed a sample of inpatients with schizophrenia or schizoaffective disorders for 16 months and found that greater support from friends at baseline predicted better satisfaction with life quality after 16 months (accounted for $2.9 \%$ of quality of life index scores at follow up examination). In an American study, greater perceived social support was

Table 3 Summary of findings on schizophrenia and schizoaffective disorders

\begin{tabular}{|c|c|c|c|c|}
\hline Reference & Predictor variable & Outcome variable & Res & $+<0.05$ adjusted; $+<0.05$ unadjusted; - non-significant) \\
\hline Ritsner et al. (2006) [58] & Perceived social support & Quality of life & ++ & $\begin{array}{l}\text { Higher friend support at baseline predicted better } \\
\text { satisfaction with life quality after } 16 \text { months } \\
\text { (accounted for } 2.9 \% \text { of quality of life index scores } \\
\text { at follow up examination) }\end{array}$ \\
\hline Brekke et al. (2005) [59] & Perceived social support & $\begin{array}{l}\text { Global functional outcome } \\
\text { (work, social functioning, and } \\
\text { independent living); } \\
\text { Social functioning domain }\end{array}$ & ++ & $\begin{array}{l}\text { Higher social support did not significantly predict } \\
\text { better global functional outcome at } 12 \text { months } \\
(p<0.10) \text {. But social support became a much } \\
\text { stronger and statistically significant predictor of } \\
\text { social functioning domain }\end{array}$ \\
\hline
\end{tabular}


a strong predictor of better scores on a social functioning domain (no effect size reported), although it did not predict the global functioning score (a composite of vocational and social functioning, and independent living) [59].However, neither of these studies adjusted for the outcome variable baseline scores.

\section{Bipolar disorder}

We found four papers that studied adults with a diagnosis of bipolar disorder (Table 4). The evidence regarding depressive symptoms was consistent and showed that lower perceived social support predicted greater depression over time (beta -0.14 to -0.25 , regression coefficient - 1.33) [60-62]. Lower perceived support was also found to be a significant predictor of greater impairment in functioning (beta -0.14 to -0.67 ) $[60,61]$, and longer time to recovery (no effect size reported) [62]. Among remitted patients with prior diagnosis of bipolar I disorder, greater perceived social support reduced risk of recurrence of any type (depressive or manic) at one year $(\mathrm{OR}=0.92$, 95\% CI 0.85-0.99) [63]. With regard to severity of manic symptoms, however, the results were not so consistent. In one study lower perceived support significantly predicted more severe manic symptoms on follow-up assessment (beta $=-0.32$ ) [61], but in other two studies it was not linked with subsequent manic symptomatology [60, 62]. Apart from the study of recurrence, the other three had adjustment for baseline score on the outcome measure.

\section{Anxiety disorders}

The three studies of patients with anxiety disorders all reported significant associations between perceived social support at baseline and outcomes at follow-up (Table 5). Two studies included people with diagnoses of generalised anxiety disorder, panic disorder, social anxiety disorder or post-traumatic stress disorder. One study found that lower perceived social support was predictive of more severe anxiety (beta $=-0.15$, CI $[-0.30,-0.06]$, Ratios $8.85 \%$ ) and depressive symptoms (beta $=-0.16$, CI $[-0.28$, 0.08 ], Ratios $10.51 \%$ ) at subsequent time points [33], and the other one found that greater perceived social support predicted a higher rate of remission at 6-month follow-up (OR $=1.38,95 \%$ CI Wald 1.09-1.75) [64]. In a study of older adults with generalised anxiety disorder, Shrestha et al. [65] found that individuals with greater perceived social support at baseline reported greater average quality of life over time (beta $=0.41$ ), albeit without adjustment for the outcome variable baseline score.

\section{Mixed samples with various mental health problems}

Two studies examined mixed samples of people with a variety of diagnoses (Table 6). Beljouw et al. [66] analysed data from primary care patients with current anxiety

Table 4 Summary of findings on bipolar disorder

\begin{tabular}{|c|c|c|c|}
\hline Reference & Predictor variable & Outcome variable & Results (++ <0.05 adjusted; $+<0.05$ unadjusted; - non-significant) \\
\hline Koenders et al. (2015) [60] & $\begin{array}{l}\text { Perceived social } \\
\text { support }\end{array}$ & $\begin{array}{l}\text { Depressive symptomatology; } \\
\text { Depression related functional } \\
\text { impairment; } \\
\text { Manic symptomatology; } \\
\text { Manic related functional } \\
\text { impairment }\end{array}$ & $\begin{array}{ll}++ & \text { Lower perceived support predicted more depression } \\
++ & \text { related functional impairment during the subsequent } \\
- & 3 \text { months }(\beta(\mathrm{SE})=-0.14(0.03), p<0.001) \text {, and with } \\
- & \text { more depressive symptomatology at the subsequent } \\
& \text { time point }(\beta(\mathrm{SE})=-0.14(0.04), p=0.002) \text {. No significant } \\
& \text { associations between perceived social support and } \\
\text { manic symptoms and impairment were observed }\end{array}$ \\
\hline Cohen et al. (2004) [63] & $\begin{array}{l}\text { Perceived social } \\
\text { support }\end{array}$ & Recurrence & $\begin{array}{l}++ \text { After controlling for clinical variables, lower social support } \\
\text { of any kind significantly predicted recurrence of any type } \\
\text { at one year ( } \beta(\mathrm{SE})=-0.09(0.04), p=0.03, \mathrm{OR}=0.92,95 \% \\
\mathrm{Cl} 0.85-0.99)\end{array}$ \\
\hline Daniels (2000) [61] & $\begin{array}{l}\text { Perceived social } \\
\text { support }\end{array}$ & $\begin{array}{l}\text { Depressive symptomatology; } \\
\text { Manic symptomatology; } \\
\text { Functional impairment }\end{array}$ & $\begin{array}{l}++ \text { Lower perceived support was a significant predictor of } \\
++ \text { more severe depressive symptomatology after controlling } \\
++ \text { for initial levels of depression }\left(R^{2}=0.67, F=34.15, \Delta R^{2}=0.05 \text {, }\right. \\
\Delta F=5.24 \text {, beta }=-0.25) \text {. Lower perceived support significantly } \\
\text { predicted more severe manic symptomatology over three } \\
\text { months }\left(R^{2}=0.18, F=3.74, \Delta R^{2}=0.10, \Delta F=4.18 \text {, beta }=-0.32\right) \text {. } \\
\text { Lower perceived social support significantly predicted impairment } \\
\text { in functioning in the participants who completed their life charts } \\
\text { for } 90 \text { consecutive days, after controlling for initial levels of } \\
\text { functional impairment }\left(R^{2}=0.44, F=5.48, \Delta R^{2}=0.41, \Delta F=10.22,\right. \\
\text { beta }=-0.67) \text {. }\end{array}$ \\
\hline Johnson et al. (1999) [62] & $\begin{array}{l}\text { Perceived social } \\
\text { support }\end{array}$ & $\begin{array}{l}\text { Time to recovery; } \\
\text { Severity of depressive } \\
\text { symptoms; } \\
\text { Severity of manic symptoms }\end{array}$ & $\begin{array}{l}++ \text { Lower social support was a significant predictor of longer time } \\
++ \text { to recovery in Cox regression survival analyses }(x 2(1, N=52) \\
-\quad \text { change }=5.89 \text {, one-tailed } p<0.01) \text {. In hierarchical multiple } \\
\text { regression analyses, low social support predicted higher } \\
\text { depression over time (regression coefficient }=-1.33, p<0.01, \\
\left.\mathrm{R}^{2} \text { change }=0.07, \mathrm{~F} \text { change }=11.70\right) \text {. Social support did not } \\
\text { have significant impact on mania score at } 6 \text {-month follow-up }\end{array}$ \\
\hline
\end{tabular}


Table 5 Summary of findings on anxiety disorders

\begin{tabular}{|c|c|c|c|}
\hline Reference & Predictor variable & Outcome variable & $\begin{array}{l}\text { Results (++ }<0.05 \text { adjusted; }+<0.05 \text { unadjusted; } \\
- \text { non-significant) }\end{array}$ \\
\hline Jakubovski and Bloch (2016) [64] & $\begin{array}{l}\text { Perceived social } \\
\text { support }\end{array}$ & $\begin{array}{l}\text { Remission; } \\
\text { Response (a reduction } \\
\text { of at least } 40 \% \text { symptoms } \\
\text { at } 6 \text { months) }\end{array}$ & $\begin{array}{l}++ \text { Generalised anxiety disorder: Greater amount of social } \\
++ \text { support predicted a higher rate of remission (OR }=1.38, \\
95 \% \mathrm{CI} \text { Wald } 1.09-1.75, p=0.0067) \text { and a greater rate of } \\
\text { response }(\mathrm{OR}=1.33,95 \% \mathrm{Cl} \text { Wald } 1.10-1.62, p=0.0040) \\
\text { at 6-month follow-up. Social anxiety disorder: Greater } \\
\text { amount of social support predicted a higher rate of } \\
\text { remission (OR }=1.716,95 \% \mathrm{Cl} \text { Wald } 1.028-2.867, \\
p=0.0391) \text { at } 6 \text {-month follow-up, but social support } \\
\text { did not predict response. Social support did not predict } \\
\text { remission or response for panic disorder or post-traumatic } \\
\text { stress disorder }\end{array}$ \\
\hline Shrestha et al. (2015) [65] & $\begin{array}{l}\text { Perceived social } \\
\text { support }\end{array}$ & Quality of life & $\begin{array}{l}++ \text { Main effect of social support was significant such that } \\
\text { those with higher baseline social support reported } \\
\text { higher average quality of life over time }(b(S E)=0.41 \\
(0.08), p<0.001)\end{array}$ \\
\hline Dour et al. (2014) [33] & $\begin{array}{l}\text { Perceived social } \\
\text { support }\end{array}$ & $\begin{array}{l}\text { Anxiety symptoms; } \\
\text { Depressive symptoms }\end{array}$ & $\begin{array}{l}++ \text { Direct effects: Relations between perceived social } \\
++ \text { support and depression were bidirectional at all } \\
\text { follow-ups, whereas they were unidirectional between } \\
\text { perceived social support and anxiety at } 6 \text { - and } 12 \text {-month } \\
\text { follow-ups. Indirect effects: Intervention led to changes in } \\
\text { 6-and/or } 12 \text {-month perceived social support, that in turn } \\
\text { led to subsequent changes in 18-month depression } \\
(b=-0.16, \mathrm{Cl}[-0.28,-0.08] \text {, Ratios } 10.51 \%) \text { and anxiety } \\
(b=-0.15, \mathrm{Cl}[-0.30,-0.06] \text {, Ratios } 8.85 \%)\end{array}$ \\
\hline
\end{tabular}

or depressive disorders, and found that greater loneliness at baseline was predictive of more severe depressive (beta $=0.89)$ or anxiety symptoms (beta $=0.40)$ at 1 -year follow-up. However, after adjustment for baseline severity of depression or anxiety, only the relationship with depression severity remained significant (beta $=0.39$ ). Fleury and colleagues [67] conducted a study among individuals with severe mental health problems including schizophrenia and other psychotic disorders and severe mood disorders. They reported that greater perceived social support was significantly predictive of higher subjective quality of life at 18 months (beta 0.136 to $0.196,95 \%$ CI 0.255 to 3.410). However, adjustments for baseline measures included functional ability in the community and diagnosis, but not baseline quality of life.

\section{Discussion \\ Main findings}

We found 34 studies that reported quantitatively on the longitudinal relationship between perceived social support/loneliness at baseline and various outcomes of mental illness at follow-up. Although substantial heterogeneity exists in the identified articles, some generalisations can be made. There is substantial evidence that less perceived social support at baseline tends to predict greater symptom severity, poorer recovery/remission and worse functional outcomes at follow-up among people with depression, and preliminary evidence of a similar relationship for people with bipolar disorder, or anxiety disorders. There is also some evidence that greater loneliness is associated with more severe

Table 6 Summary of findings on mixed samples with various mental health problems

\begin{tabular}{|c|c|c|c|}
\hline Reference & Predictor variable & Outcome variable & Results (++ $<0.05$ adjusted; $+<0.05$ unadjusted; - non-significant) \\
\hline Fleury et al. (2013) [67] & $\begin{array}{l}\text { Perceived social } \\
\text { support }\end{array}$ & $\begin{array}{l}\text { Subjective quality } \\
\text { of life }\end{array}$ & $\begin{array}{l}++ \text { Social support variables at baseline accounted for } 7.9 \% \text { of } \\
\text { quality of life at } 18 \text {-month follow-up. Among social support } \\
\text { dimensions, higher perception of availability of social integration } \\
(\beta=0.196, t=3.472, p=0.001,95 \% \mathrm{Cl}[0.942,3.410]) \text { and reassurance } \\
\text { of worth supports ( } \beta=0.136, t=2.397, p=0.017,95 \% \mathrm{Cl}[0.255,2.597] \\
\text { at baseline predicted better quality of life at } 18 \text {-month follow-up }\end{array}$ \\
\hline Van Beljouw et al. (2010) [66] & Loneliness & $\begin{array}{l}\text { Severity of } \\
\text { depression; } \\
\text { Severity of anxiety }\end{array}$ & $\begin{array}{l}++ \text { A higher symptom severity in depression at } 1 \text {-year follow-up was } \\
+\quad \text { predicted by more loneliness at baseline in both multilevel univariate } \\
\text { linear regression analyses }(\beta=0.89, \mathrm{SE}=0.17, p<0.001) \text { and multilevel } \\
\text { multivariate linear regression analyses }(\beta=0.39, \mathrm{SE}=0.16, p<0.05) \\
\text { Positive associations were found between more symptom severity } \\
\text { in anxiety at } 1 \text {-year follow-up and loneliness at baseline by multilevel } \\
\text { univariate linear regression analyses }(\beta=0.40, \mathrm{SE}=0.12, p<0.01) \text { (but } \\
\text { not significant in multivariate analyses) }\end{array}$ \\
\hline
\end{tabular}


depression and anxiety symptoms and poorer remission from depression. An important consideration in interpreting findings is that depression is very likely to make people more likely to appraise their social support as inadequate and to feel emotionally lonely. However, a persistent effect on outcomes is found in many studies with adjustment for baseline depression severity. With regard to schizophrenia/schizoaffective disorders, only functional outcomes have been studied and the small amount of available evidence suggests that greater perceived social support is predictive of better subjective quality of life and social functioning. This review, to our knowledge, is the first to systematically examine longitudinal studies regarding the relationship between loneliness and closely related concepts and outcomes for adults of all ages and all types of mental illness.

\section{Strengths and limitations of the included studies and of this review}

Generally, the quality of included studies is acceptable and most studies were assigned at least ${ }^{* * *}$ as their overall quality scores in accordance with the methodological quality criteria of MMAT. However, some methodological issues in the published literature may limit what can be inferred from the studies. Many studies did not have comprehensive information about percentage of complete outcome data, baseline response rate, or follow-up rate, resulting in lower quality assessment ratings. We did assess whether studies adjusted for baseline measurements on the outcomes. Some did not, increasing uncertainty about the direction of causation (although if the baseline outcome measure which included random errors was introduced as a covariate, regression to the mean might lead to biased results according to Lord's paradox [68]). A large majority of the 23 studies that did adjust for baseline outcome measures still found loneliness/perceived social support to be predictive of outcomes. This suggests that there is a real effect of loneliness/lack of social support on outcomes. However, it is likely that the relationship can be a circular one, with loneliness/lack of social support resulting in more severe symptoms, and more severe symptoms exacerbating loneliness/lack of social support.

The consistency of findings across a variety of settings, measures of the exposure, and population groups increases confidence in the generalisability of the review's findings. The retrieved articles encompassed varying populations including older and younger groups, and people recruited in primary care, inpatient and outpatient settings, and were carried out around the world. Most studies of perceived social support used well-developed scales where psychometric properties have been established. The measures used varied regarding the dimensions and types of social support assessed, although they all measure individuals' subjective appraisal of adequacy or impact of their relationships rather than objective or structural social support. Both loneliness studies used a published measure of loneliness with well-established psychometric properties, but this review shows that knowledge about the relationship between loneliness and outcomes of mental health problems is still very limited. Finally, the studies in our review had sample sizes ranging from 42 to 1004, and diverse follow-up periods from a few months to ten years. The sample size of most studies is under 400 with less than 100 participants in six articles. However, the consistency of positive findings from included studies, irrespective of their sample size, provides some confidence that studies were not underpowered.

Other limitations of this review relate to the search strategy. Although our literature search was conducted in six databases and a variety of search terms were applied, the search might not be exhaustive. Some relevant studies may have been missed if they did not use "subjective or personal or perceived or quality" five or fewer words apart from "social support". Some very old papers might not be indexed in electronic databases, and thus cannot be searched. Eligible studies are only from seven countries and most of them were conducted in North America. Very few papers in other languages were retrieved and none of them could be included in our review, although we did search for them and read their abstracts. It is also worth noting that the extent of any reporting bias is uncertain as studies which did not find a positive result might not be published. Another limitation refers to the scope of our review. We restricted the search to the most common mental disorders, including schizophrenia and schizoaffective disorder, psychosis in general, depression, bipolar disorder, and anxiety disorders. The associations between loneliness and perceived social support and other mental health problems need further investigation. Additionally, we focused on one direction of causation only: the effect of baseline loneliness and poor perceived social support on mental health outcomes at follow up. Psychiatric symptoms probably also influence loneliness and perceived social support, but this was not the research question on which we focused in this review.

\section{Research implications}

Most studies included in our review focused on depression, with other types of mental health problems represented by fewer than five studies each. Nevertheless, some significant relationships have been found between loneliness and/or perceived social support and outcomes of those mental disorders. Gayer-Anderson and Morgan [46] systematically examined evidence on social networks and social support in early psychosis. They found 
some tentative evidence that deficits in social networks and support preceded the onset of psychosis, but it was difficult to disentangle direction of causation as almost all the studies included were cross-sectional and they did not report whether social relationships influence outcomes of psychosis. Given that the prevalence of loneliness in people with psychosis was comparable to that in people with depression, it is surprising that research about impact of loneliness/perceived social support on psychosis is scarce. Similarly, social relationships were shown to be related to bipolar disorder and anxiety disorders, but there is a lack of evidence to discern cause and effect $[69,70]$. Therefore more systematic exploration is needed about how loneliness and perceived social support affect conditions such as psychosis, bipolar disorder and anxiety disorders.

Additionally, more longitudinal research with long-term follow-up (and repeated measures) is essential to untangle the direction of effect in the relationship between loneliness/perceived social support and poor outcomes. Among the 34 eligible studies only five articles involve a long-term follow-up period (over 2 years). Thus there is a need to establish the longer term associations of loneliness and perceived social support. As well its effects on longer term mental health outcomes, loneliness may contribute to the adverse physical health outcomes and increased mortality of people with severe mental health problems.

We also found that the relationship between perceived social support and depression was studied far more often and is thus far more clearly established than the relationship between loneliness and depression. Only two studies retrieved for our review included loneliness as an independent variable for outcomes of mental disorders. They found that loneliness at baseline predicted depression and anxiety severity and remission from depression $[25,66]$. However, the few longitudinal studies of loneliness do not allow definitive conclusions. Therefore more longitudinal research is needed in clinical samples to try to achieve a clear understanding of the impact of loneliness on the course of mental health problems.

\section{Clinical and policy implications}

There are a number of clinical and policy implications from the finding that poor perceived social support has a significant impact on outcomes in depression. Firstly, it highlights the need to pay sufficient attention to the social relationships and social support needs of people with mental health problems. Social activities, or thinking about relationships, can be overlooked in clinical consultations - in favour of medications or psychological therapies, and there have been recent calls to raise the profile of social factors in mental health care and mental health research [16]. Raising practitioners' awareness of the beneficial effects of good perceived social support on symptoms, recovery, and functioning is an important first step, but also promoting awareness amongst service users and the wider public - so that people may feel more motivated to seek relevant help or to try to change their own situation, particularly in depression but probably in other mental health problems studied too.

The development of effective interventions to promote social support and reduce loneliness is required to address the current evidence gap, manifested by the absence of recommendations in this important social domain in current policy guidance. In the UK for example, the National Health Service (NHS) Five Year Forward View [71] refers to a series of plans to improve the quality of mental health services and reduce 'burden' on the NHS. Access to psychological therapies, waiting standards and better physical healthcare are highlighted but there is no specific mention of managing the significant problems of loneliness or limited social relationships. International evidence that poor perceived support from social relationships leads to increased service use and poorer outcomes across a range of diagnostic groups should inform future policy in this area. Also in the UK, the latest National Institute for Clinical Excellence (NICE) guidance on illnesses such as depression and schizophrenia, does not recommend social interventions apart from employment support [72, 73].

Clinicians may doubt whether loneliness and limited support from interpersonal relationships are appropriate or feasible as targets for intervention. However, potential interventions are becoming available in a variety of sectors. Around the world, approaches are being developed to try to reduce loneliness among older people in the general population, with potential to be adapted to other groups in the population at risk of adverse effects from poor social support. In the UK, a variety of approaches to social relationships and social participation are being developed primarily in the charitable sector and in primary care [74]. Social prescribing projects have proliferated in the UK in recent years [75]. Social prescribing is not precisely defined, but typically refers to: navigation - the process of linking support for people to access community activities helpful to wellbeing and participation; and/or funding and providing these activities in a community or group setting [76]. As yet however, social prescribing models are numerous and poorly defined [75], and there is a lack of robust evidence regarding their effectiveness [76]. Psychological approaches, such as Cognitive Behavioural Therapy and Mindfulness, have also been used to help people change their thinking about social relationships: some promising results have been reported, especially with older adult populations [77]. Thus there are approaches available with potential to be adapted and tested for people with mental health problems, to try to alleviate the adverse effects identified in this paper. There is 
also a need to consider public understanding of the importance of nurturing social relationships, as the high prevalence of loneliness is not only an individual but necessarily also a community and societal level problem. Thus people with mental health problems, like other groups in the population who are vulnerable to the effects of loneliness, are likely to benefit from an approach to loneliness that also takes account of community resources and how they might be enhanced [78].

\section{Conclusions}

This systematic review has identified prospective studies in the area of loneliness/perceived social support and outcomes of mental health problems. We found substantial evidence that in depression, poorer perceived social support is associated with poorer outcomes in terms of symptoms, recovery and functioning. There is some preliminary evidence of a similar relationship in bipolar and anxiety disorders, and of a relationship between greater perceived social support and better quality of life and functioning in schizophrenia. Loneliness and its impact on mental health outcomes are still insufficiently addressed compared to perceived social support, but there is some evidence that greater loneliness is related to more severe depression and anxiety symptoms and poorer remission from depression. Further research, including long-term follow-up and repeated measures, is required to longitudinally investigate the direction of effect between loneliness/perceived social support and poor mental health outcomes among service users from different diagnostic groups. There is also a case, especially in depression, for raising public awareness of the importance of reducing public health, and for developing, testing and implementing strategies to improve perceived social support and reduce loneliness in people with mental health problems.

\section{Additional files}

Additional file 1: Search strategies (detailed search strategies used in Medline, PsycINFO, Embase, Web of Science, CINAHL and Cochrane Library). (PDF $323 \mathrm{~kb}$ )

Additional file 2: Criteria for quality assessment and study evaluation table (study description table including author, year and country of each publication, study population, sample size, length of follow-up period, follow-up rate achieved, predictor variable, outcome variable and Study quality assessment rating). (PDF $280 \mathrm{~kb}$ )

\footnotetext{
Abbreviations

CES-D: Center for Epidemiologic Studies Depression Scale; DSM: Diagnostic and Statistical Manual of Mental Disorder; HoNOS: Health of the Nation Outcome Scales; ICD: International Classification of Diseases; M.I.N.I. : MiniInternational Neuropsychiatric Interview; MMAT: Mixed Methods Appraisal Tool; NHS: National Health Service; NICE: National Institute for Clinical Excellence; PTSD: post-traumatic stress disorder; UCLA: University of California at Los Angeles Loneliness Scale
}

\section{Acknowledgments}

We are grateful for the help of UCL Library staff for consultation and guidance in the search strategy. We would like to thank the authors of screened papers who responded to our emails for their support.

\section{Authors' contributions}

SJ, JW and BLE conceived the review. SJ and BLE commented on search strategy and review protocol. JW developed the search strategy and review protocol, did the systematic search, and wrote the first draft and co-ordinated further drafts. JW and FM independently screened and selected papers for inclusion, extracted data, and assessed the methodological quality of each study. RM helped screen reference lists of included studies and extract data from relevant studies. SJ resolved queries about inclusion/exclusion and disagreements between JW and FM during the review process. SJ, BLE, FM, and RM contributed comments and suggestions to the drafts. All authors read and approved the final manuscript.

\section{Ethics approval and consent to participate}

Not applicable.

\section{Competing interests}

The authors declare that they have no competing interests.

\section{Publisher's Note}

Springer Nature remains neutral with regard to jurisdictional claims in published maps and institutional affiliations.

Received: 20 October 2017 Accepted: 11 May 2018

Published online: 29 May 2018

\section{References}

1. Umberson D, Montez JK. Social relationships and health: a flashpoint for health policy. J Health Soc Behav. 2010;51:S54-66.

2. Hawkley LC, Cacioppo JT. Loneliness matters: a theoretical and empirical review of consequences and mechanisms. Ann Behav Med. 2010;40(2):218-27.

3. Petitte T, Mallow J, Barnes E, Petrone A, Barr T, Theeke L. A systematic review of loneliness and common chronic physical conditions in adults. Open Psychol J. 2015;8(Suppl 2):113-32.

4. Uchino BN. Understanding the links between social support and physical health: a life-span perspective with emphasis on the Separability of perceived and received support. Perspect Psychol Sci. 2009;4(3):236-55.

5. Holt-Lunstad J, Smith TB, Baker M, Harris T, Stephenson D. Loneliness and social isolation as risk factors for mortality: a meta-analytic review. Perspect Psychol Sci. 2015;10(2):227-37.

6. Holt-Lunstad J, Smith TB, Layton JB. Social Relationships and mortality risk: a meta-analytic review. PLoS Med. 2010;7(7)

7. Valtorta NK, Kanaan M, Gilbody S, Ronzi S, Hanratty B. Loneliness and social isolation as risk factors for coronary heart disease and stroke: systematic review and meta-analysis of longitudinal observational studies. Heart. 2016; 102(13):1009-16.

8. Hawkley LC, Thisted RA, Masi CM, Cacioppo JT. Loneliness predicts increased blood pressure: 5-year cross-lagged analyses in middle-aged and older adults. Psychol Aging. 2010;25(1):132-41.

9. Yang YC, Boen C, Harris KM. Social relationships and hypertension in late life: evidence from a nationally representative longitudinal study of older adults. J Aging Health. 2015;27(3):403-31.

10. Jaremka LM, Andridge RR, Fagundes CP, Alfano CM, Povoski SP, Lipari AM, Agnese DM, Arnold MW, Farrar WB, Yee LD, et al. Pain, depression, and fatigue: loneliness as a longitudinal risk factor. Health Psychol. 2014;33(9):948-57.

11. Hughes S, Jaremka LM, Alfano CM, Glaser R, Povoski SP, Lipari AM, Agnese DM, Farrar WB, Yee LD, Carson WE, et al. Social support predicts inflammation, pain, and depressive symptoms: longitudinal relationships among breast cancer survivors. Psychoneuroendocrinology. 2014;42:38-44.

12. House JS, Landis KR, Umberson D. Social relationships and health. Science. 1988:241(4865):540-5

13. Cacioppo JT, Cacioppo S, Boomsma DI. Evolutionary mechanisms for loneliness. Cogn Emot. 2014;28(1):3-21.

14. Perese EF, Wolf M. Combating loneliness among persons with severe mental illness: social network interventions' characteristics, effectiveness, and applicability. Issues Ment Health Nurs. 2005;26(6):591-609. 
15. Howes OD, Murray RM. Schizophrenia: an integrated sociodevelopmentalcognitive model. Lancet. 2014;383(9929):1677-87.

16. Johnson S. Social interventions in mental health: a call to action. Soc Psychiatry Psychiatr Epidemiol. 2017;52(3):245-7.

17. Reininghaus $U$, Morgan $C$. Integrated models in psychiatry: the state of the art. Soc Psychiatry Psychiatr Epidemiol. 2014;49(1):1-2.

18. Peplau LA, Perlman D. Loneliness: A Sourcebook of current theory, Research, and Therapy. New York: Wiley Interscience; 1982.

19. Weiss RS. Loneliness: the experience of emotional and social isolation. Cambridge, MA. In: US: the MIT press; 1973.

20. Gierveld JD, Van Tilburg T. A 6-item scale for overall, emotional, and social loneliness - confirmatory tests on survey data. Res Aging. 2006;28(5):582-98.

21. Russell DW. UCLA loneliness scale (version 3): reliability, validity, and factor structure. J Pers Assess. 1996;66(1):20-40.

22. Dejonggierveld J, Kamphuis F. The development of a rasch-type loneliness scale. Appl Psychol Meas. 1985;9(3):289-99.

23. Borge L, Martinsen EW, Ruud T, Watne O, Friis S. Quality of life, loneliness, and social contact among long-term psychiatric patients. Psychiatr Serv. 1999:50(1):81-4.

24. Lauder W, Sharkey S, Mummery K. A community survey of loneliness. J Adv Nurs. 2004;46(1):88-94

25. Holvast F, Burger H, de Waal MMW, van Marwijk HWJ, Comijs HC, Verhaak PFM. Loneliness is associated with poor prognosis in late-life depression: longitudinal analysis of the Netherlands study of depression in older persons. J Affect Disord. 2015;185:1-7.

26. van Tilburg TG, de Jong Gierveld J. Reference standards for the loneliness scale. Tijdschr Gerontol Geriatr. 1999;30(4):158-63.

27. Badcock JC, Shah S, Mackinnon A, Stain HJ, Galletly C, Jablensky A, Morgan VA. Loneliness in psychotic disorders and its association with cognitive function and symptom profile. Schizophr Res. 2015;169(1-3):268-73.

28. Victor CR, Yang KM. The prevalence of loneliness among adults: a case study of the United Kingdom. Aust J Psychol. 2012;146(1-2):85-104.

29. Meltzer H, Bebbington P, Dennis MS, Jenkins R, McManus S, Brugha TS Feelings of loneliness among adults with mental disorder. Soc Psychiatry Psychiatr Epidemiol. 2013;48(1):5-13.

30. Routasalo PE, Savikko N, Tilvis RS, Strandberg TE, Pitkala KH. Social contacts and their relationship to loneliness among aged people - a populationbased study. Gerontology. 2006;52(3):181-7.

31. Coyle CE, Dugan E. Social isolation, loneliness and health among older adults. J Aging Health. 2012;24(8):1346-63.

32. Wang JY, Lloyd-Evans B, Giacco D, Forsyth R, Nebo C, Mann F, Johnson S. Social isolation in mental health: a conceptual and methodological review. Soc Psychiatry Psychiatr Epidemiol. 2017;52(12):1451-61.

33. Dour HJ, Wiley JF, Roy-Byrne P, Stein MB, Sullivan G, Sherbourne CD, Bystritsky A, Rose RD, Craske MG. Perceived social support mediates anxiety and depressive symptom changes following primary care intervention. Depress Anxiety. 2014;31(5):436-42.

34. Hupcey JE. Clarifying the social support theory-research linkage. J Adv Nurs. 1998;27(6):1231-41.

35. Zimet GD, Dahlem NW, Zimet SG, Farley GK. The multidimensional scale of perceived social support. J Pers Assess. 1988;52(1):30-41.

36. Koenig HG, Westlund RE, George LK, Hughes DC, Blazer DG, Hybels C. Abbreviating the Duke social support index for use in chronically ill elderly individuals. Psychosomatics. 1993;34(1):61-9.

37. Brown GW, Harris T. Social origins of depression. London: Tavistock; 1978.

38. Murphy E. Social origins of depression in old-age. Br J Psychiatry. 1982;141:135-42.

39. Salimi A, Bozorgpour F. Percieved Social Support and Social-Emotional Loneliness. In: International Conference on Education \& Educational Psychology. Volume 69 ed. Amsterdam: Elsevier Science Bv; 2012. p. 2009-13.

40. Pamukcu B, Meydana B. The role of empathic tendency and perceived social support in predicting loneliness levels of college students. In: Wcpco 2010. Volume 5 ed. Amsterdam: Elsevier Science Bv; 2010. p. 905-9.

41. Lasgaard M, Nielsen A, Eriksen ME, Goossens L. Loneliness and social support in adolescent boys with autism Spectrum disorders. J Autism Dev Disord. 2010;40(2):218-26.

42. Chrostek A, Grygiel P, Anczewska M, Wciorka J, Switaj P. The intensity and correlates of the feelings of loneliness in people with psychosis. Compr Psychiatry. 2016;70:190-9.

43. Gariepy G, Honkaniemi H, Quesnel-Vallee A. Social support and protection from depression: systematic review of current findings in western countries. Br J Psychiatry. 2016;209(4):286-95.
44. Santini Zl, Koyanagi A, Tyrovolas S, Mason C, Haro JM. The association between social relationships and depression: a systematic review. J Affect Disord. 2015;175:53-65.

45. Schwarzbach M, Luppa M, Forstmeier S, Konig HH, Riedel-Heller SG. Social relations and depression in late life - a systematic review. Int J Geriatr Psychiatry. 2014;29(1):1-21.

46. Gayer-Anderson C, Morgan C. Social networks, support and early psychosis: a systematic review. Epidemiol Psychiatr Sci. 2013;22(2):131-46.

47. Wang J, Mann F, Lloyd-Evans B, Ma R, Johnson S. Loneliness as a predictor of outcomes in mental disorders: a systematic review. PROSPERO International prospective register of systematic reviews. 2014; http://www.crd.york.ac.uk/ PROSPERO/display_record.asp?ID=CRD42015014784. Accessed 19 Oct 2016

48. Pluye P, Robert E, Cargo M, Bartlett G, O'Cathain A, Griffiths F, Boardman F, Gagnon MP, Rousseau MC. Proposal: A Mixed Methods Appraisal Tool for Systematic Mixed Studies Reviews. Canada: Department of Family Medicine, McGill University, Montreal; 2011. http://mixedmethodsappraisaltoolpublic. pbworks.com. Accessed 19 Oct 2016

49. Blazer D, Hughes DC, George LK. Age and impaired subjective support. Predictors of depressive symptoms at one-year follow-up J Nerv Ment Dis. 1992;180(3):172-8.

50. Brugha TS, Bebbington PE, Maccarthy B, Sturt E, Wykes T, Potter J. Gender, social support and recovery from depressive disorders: a prospective clinical study. Psychol Med. 1990;20(1):147-56.

51. Leskela U, Rytsala $H$, Komulainen E, Melartin T, Sokero P, Lestela-Mielonen P, Isometsa $\mathrm{E}$. The influence of adversity and perceived social support on the outcome of major depressive disorder in subjects with different levels of depressive symptoms. Psychol Med. 2006;36(6):779-88.

52. Bosworth HB, Hays JC, George LK, Steffens DC. Psychosocial and clinical predictors of unipolar depression outcome in older adults. Int J Geriatr Psychiatry. 2002;17(3):238-46.

53. Bosworth HB, McQuoid DR, George LK, Steffens DC. Time-to-remission from geriatric depression: psychosocial and clinical factors. Am J Geriatr Psychiatry. 2002;10(5):551-9.

54. Holma I, Holma K, Melartin T, Rytsala H, Isometsa E. A 5-year prospective study of predictors for disability pension among patients with major depressive disorder. Acta Psychiatr Scand. 2012;125(4):325-34.

55. Rytsala H, Melartin T, Leskela U, Sokero T, Lestela-Mielonen P, Isometsa E. Predictors of long-term work disability in major depressive disorder: a prospective study. Acta Psychiatr Scand. 2007;115(3):206-13.

56. Rytsala HJ, Melartin TK, Leskela US, Lestela-Mielonen PS, Sokero T, Isometsa ET. Determinants of functional disability and social adjustment in major depressive disorder: a prospective study. J Nerv Ment Dis. 2006;194(8):570-6

57. Hays JC, Steffens DC, Flint EP, Bosworth HB, George LK. Does social support buffer functional decline in elderly patients with unipolar depression? Am J Psychiatry. 2001;158(11):1850-5.

58. Ritsner M, Gibel A, Ratner Y. Determinants of changes in perceived quality of life in the course of schizophrenia. Qual Life Res. 2006;15(3):515-26.

59. Brekke J, Kay DD, Lee KS, Green MF. Biosocial pathways to functional outcome in schizophrenia. Schizophr Res. 2005:80(2-3):213-25.

60. Koenders MA, Giltay EJ, Hoencamp E, Elzinga BM, Spinhoven P, Spijker AT. The bidirectional impact of perceived and enacted support on mood in bipolar outpatients: a two-year prospective study. Compr Psychiatry. 2015;60:59-67.

61. Daniels RE. Psychosocial predictors of symptom severity and functioning in adults with bipolar disorder. A three-month prospective study. Diss Abstr Int B Sci Eng. 2000;60(8-B):4213.

62. Johnson SL, Winett CA, Meyer B, Greenhouse WJ, Miller I. Social support and the course of bipolar disorder. J Abnorm Psychol. 1999;108(4):558-66.

63. Cohen AN, Hammen C, Henry RM, Daley SE. Effects of stress and social support on recurrence in bipolar disorder. J Affect Disord. 2004;82(1):143-7.

64. Jakubovski E, Bloch MH. Anxiety disorder-specific predictors of treatment outcome in the coordinated anxiety learning and management (CALM) trial. Psychiatr Q. 2016;87(3):445-64.

65. Shrestha S, Stanley MA, Wilson NL, Cully JA, Kunik ME, Novy DM, Rhoades $\mathrm{HM}$, Amspoker AB. Predictors of change in quality of life in older adults with generalized anxiety disorder. Int Psychogeriatr. 2015;27(7):1207-15.

66. van Beljouw IM, Verhaak PF, Cuijpers P, van Marwijk HW, Penninx BW. The course of untreated anxiety and depression, and determinants of poor oneyear outcome: a one-year cohort study. BMC Psychiatry. 2010;10:86.

67. Fleury MJ, Grenier G, Bamvita JM, Tremblay J, Schmitz N, Caron J. Predictors of quality of life in a longitudinal study of users with severe mental disorders. Health Qual Life Outcomes. 2013;11(1) 
68. Eriksson K, Haggstrom O. Lord's paradox in a continuous setting and a regression artifact in numerical cognition research. PLoS One. 2014;9(4)

69. Studart PM, Bezerra S, Studart ABD, Galvao-de Almeida A, Miranda-Scippa A. Social support and bipolar disorder. Arch Clin Psychiatry. 2015;42(4):95-9.

70. Teo AR, Lerrigo R, Rogers MAM. The role of social isolation in social anxiety disorder: a systematic review and meta-analysis. J Anxiety Disord. 2013;27(4):353-64.

71. NHS Five Year Forward View. 2014. https://www.england.nhs.uk/wpcontent/uploads/2014/10/5yfv-web.pdf. Accessed 19 Oct 2016.

72. Psychosis and schizophrenia in adults: prevention and management. National Institute for Health and Care Excellence (NICE). 2014. https://www. nice.org.uk/guidance/cg178. Accessed 19 Oct 2016.

73. Continuation and relapse prevention for adults with depression. National Institute for Health and Care Excellence (NICE). 2016. https://pathways.nice. org.uk/pathways/depression/continuation-and-relapse-prevention-for-adultswith-depression\#path=view\%3A/pathways/depression/continuation-andrelapse-prevention-for-adults-with-depression.xml\&content=view-index. Accessed 19 Oct 2016

74. Mann F, Bone JK, Lloyd-Evans B, Frerichs J, Pinfold V, Ma R, Wang J, Johnson S. A life less lonely: the state of the art in interventions to reduce loneliness in people with mental health problems. Soc Psychiatry Psychiatr Epidemiol. 2017;52(6):627-38

75. Report of the Annual Social Prescribing Network Conference. London: University of Westminster; 2016

76. Evidence to inform the commissioning of social prescribing. York: University of York. Centre for reviews and dissemination; 2015.

77. Masi CM, Chen HY, Hawkley LC, Cacioppo JT. A meta-analysis of interventions to reduce loneliness. Personal Soc Psychol Rev. 2011;15(3):219-66.

78. Kearns A, Whitley E, Tannahill C, Ellaway A. Loneliness, social relations and health and well-being in deprived communities. Psychol Health Med. 2015; 20(3):332-44.

79. Hybels CF, Pieper CF, Blazer DG, Steffens DC. Heterogeneity in the threeyear course of major depression among older adults. Int J Geriatr Psychiatr. 2016;31(7):775-82.

80. Backs-Dermott BJ, Dobson KS, Jones SL. An evaluation of an integrated model of relapse in depression. J Affect Disord. 2010;124(1-2):60-7.

81. Bosworth HB, Voils Cl, Potter GG, Steffens DC. The effects of antidepressant medication adherence as well as psychosocial and clinical factors on depression outcome among older adults. Int J Geriatr Psychiatry. 2008;23(2):129-34.

82. Steffens DC, Pieper CF, Bosworth HB, MacFall JR, Provenzale JM, Payne ME, Carroll BJ, George LK, Krishnan KRR. Biological and social predictors of longterm geriatric depression outcome. Int Psychogeriatr. 2005;17(1):41-56.

83. Ezquiaga E, Garcia-Lopez A, de Dios C, Leiva A, Bravo M, Montejo J. Clinical and psychosocial factors associated with the outcome of unipolar major depression: a one year prospective study. J Affect Disord. 2004;79(1-3):63-70.

84. Gasto C, Navarro V, Catalan R, Portella MJ, Marcos T. Residual symptoms in elderly major depression remitters. Acta Psychiatr Scand. 2003;108(1):15-9.

85. Triesch SK. Interpersonal expectations and adjustment to depression. Diss Abstr Int B Sci Eng. 2002;63(3-B):1578.

86. Oxman TE, Hull JG. Social support and treatment response in older depressed primary care patients. J Gerontol B Psychol Sci Soc Sci. 2001;56(1):P35-45.

87. Brummett BH, Barefoot JC, Siegler IC, Steffens DC. Relation of subjective and received social support to clinical and self-report assessments of depressive symptoms in an elderly population. J Affect Disord. 2000;61(1-2):41-50.

88. Sherbourne CD, Hays RD, Wells KB. Personal and psychosocial risk factors for physical and mental health outcomes and course of depression among depressed patients. J Consult Clin Psychol. 1995;63(3):345-55.

89. Blazer D, Hughes DC. Subjective social support and depressive symptoms in major depression: separate phenomena or epiphenomena. J Psychiatr Res. 1991;25(4):191-203.

90. George LK, Blazer DG, Hughes DC, Fowler N. Social support and the outcome of major depression. Br J Psychiatry. 1989;154:478-85.

91. Krantz SE, Moos RH. Risk factors at intake predict nonremission among depressed patients. J Consult Clin Psychol. 1988;56(6):863-9.

\section{Ready to submit your research? Choose BMC and benefit from:}

- fast, convenient online submission

- thorough peer review by experienced researchers in your field

- rapid publication on acceptance

- support for research data, including large and complex data types

- gold Open Access which fosters wider collaboration and increased citations

- maximum visibility for your research: over $100 \mathrm{M}$ website views per year

At BMC, research is always in progress.

Learn more biomedcentral.com/submissions 